\title{
Quantitative Analysis of Norepinephrine Transporter in the Human Brain Using PET with $(\mathrm{S}, \mathrm{S})-{ }^{18} \mathrm{~F}-\mathrm{FMeNER}-\mathrm{D}_{2}$
}

\author{
Ryosuke Arakawa ${ }^{1,2}$, Masaki Okumura ${ }^{1,2}$, Hiroshi Ito $^{1}$, Chie Seki ${ }^{1}$, Hidehiko Takahashi ${ }^{1}$, Harumasa Takano $^{1}$, \\ Ryuji Nakao ${ }^{3}$, Kazutoshi Suzuki ${ }^{3}$, Yoshiro Okubo ${ }^{2}$, Christer Halldin ${ }^{4}$, and Tetsuya Suhara ${ }^{1}$
}

${ }^{1}$ Molecular Neuroimaging Group, Molecular Imaging Center, National Institute of Radiological Sciences, Chiba, Japan; ${ }^{2}$ Department of Neuropsychiatry, Nippon Medical School, Tokyo, Japan; ${ }^{3}$ Molecular Probe Group, Molecular Imaging Center, National Institute of Radiological Sciences, Chiba, Japan; and ${ }^{4}$ Psychiatry Section, Department of Clinical Neuroscience, Karolinska Institutet, Karolinska Hospital, Stockholm, Sweden

$(\mathrm{S}, \mathrm{S})-{ }^{18} \mathrm{~F}-\mathrm{FMeNER}-\mathrm{D}_{2}$ was recently developed as a radioligand for the measurement of norepinephrine transporter imaging with PET. In this study, a norepinephrine transporter was visualized in the human brain using this radioligand with PET and quantified by several methods. Methods: PET scans were performed on 10 healthy men after intravenous injection of $(\mathrm{S}, \mathrm{S}){ }^{18} \mathrm{~F}$ FMeNER- $D_{2}$. Binding potential relative to nondisplaceable binding $\left(\mathrm{BP}_{\mathrm{ND}}\right)$ was quantified by the indirect kinetic, simplified reference-tissue model (SRTM), multilinear reference-tissue model (MRTM), and ratio methods. The indirect kinetic method was used as the gold standard and was compared with the SRTM method with scan times of 240 and $180 \mathrm{~min}$, the MRTM method with a scan time of $240 \mathrm{~min}$, and the ratio method with a time integration interval of $120-180 \mathrm{~min}$. The caudate was used as reference brain region. Results: Regional radioactivity was highest in the thalamus and lowest in the caudate during $\mathrm{PET}$ scanning. $\mathrm{BP}_{\mathrm{ND}}$ values by the indirect kinetic method were $0.54 \pm 0.19$ and $0.35 \pm 0.25$ in the thalamus and locus coeruleus, respectively. $\mathrm{BP}_{\mathrm{ND}}$ values found by the SRTM, MRTM, and ratio methods agreed with the values demonstrated by the indirect kinetic method $(r=0.81-0.92)$. Conclusion: The regional distribution of $(\mathrm{S}, \mathrm{S})-{ }^{18} \mathrm{~F}-\mathrm{FMeNER}-\mathrm{D}_{2}$ in our study agreed with that demonstrated by previous PET and postmortem studies of norepinephrine transporter in the human brain. The ratio method with a time integration interval of 120-180 min will be useful for clinical research of psychiatric disorders for estimation of norepinephrine transporter occupancy by antidepressants without requiring arterial blood sampling and dynamic PET.

Key Words: norepinephrine transporter; (S,S)- ${ }^{18} \mathrm{~F}-\mathrm{FMeNER}-\mathrm{D}_{2}$; positron emission tomography; human brain; thalamus

J Nucl Med 2008; 49:1270-1276

DOI: 10.2967/jnumed.108.051292

Received Jan. 30, 2008; revision accepted May 2, 2008.

For correspondence or reprints contact: Hiroshi Ito, Molecular Neuroimaging Group, Molecular Imaging Center, National Institute of Radiological Sciences,

4-9-1, Anagawa, Inage-ku, Chiba, 263-8555, Japan.

E-mail: hito@nirs.go.jp

COPYRIGHT @ 2008 by the Society of Nuclear Medicine, Inc.
$\mathbf{N}$ orepinephrine, one of the monoamine neurotransmitters in the central nervous system, has been reported to be related to several functions such as memory, cognition, consciousness, and emotion and to play important roles in psychiatric disorders $(1-4)$. Norepinephrine transporter is responsible for the reuptake of norepinephrine into presynaptic nerves. Norepinephrine reuptake inhibitors are used for the treatment of depression and attention deficit hyperactivity disorder (ADHD) (4-7). Thus, changes in norepinephrine transporter functions in several psychiatric disorders can be expected, but in vivo estimation has not been performed because of a lack of suitable radioligands for norepinephrine transporters.

$(\mathrm{S}, \mathrm{S})-{ }^{18} \mathrm{~F}-\mathrm{FMeNER}-\mathrm{D}_{2}$ has recently been developed as a radioligand for the measurement of norepinephrine transporter for PET (8). (S,S)- ${ }^{18} \mathrm{~F}-\mathrm{FMeNER}-\mathrm{D}_{2}$ is a reboxetine analog and has high affinity for norepinephrine transporter and high selectivity from other monoamine transporters. Tracer distribution and dosimetry of $(\mathrm{S}, \mathrm{S})-{ }^{18} \mathrm{~F}-\mathrm{FMeNER}-\mathrm{D}_{2}$ were reported in monkey $(8,9)$ and human studies $(10,11)$. Another monkey study showed that $(\mathrm{S}, \mathrm{S})-{ }^{18} \mathrm{~F}-\mathrm{FMeNER}-\mathrm{D}_{2}$ binding decreased by the administration of atomoxetine, a selective norepinephrine reuptake inhibitor (12). However, quantitative analyses of $(\mathrm{S}, \mathrm{S})-{ }^{18} \mathrm{~F}-\mathrm{FMeNER}-\mathrm{D}_{2}$ bindings using an arterial input function have not yet, to our knowledge, been performed.

In this study, we aimed to quantify the norepinephrine transporter bindings in the human brain using $(\mathrm{S}, \mathrm{S})-{ }^{18} \mathrm{~F}-$ FMeNER-D 2 with arterial blood sampling and also to validate noninvasive methods for quantification without arterial blood sampling.

\section{MATERIALS AND METHODS}

\section{Subjects}

Ten healthy men (age range, 21-26 y; mean \pm SD, $22.7 \pm$ 1.6 y) participated in this study. All subjects were free of any somatic, neurologic, or psychiatric disorders, and they had no 
history of current or previous drug abuse. Written informed consent was obtained from all subjects following a complete description of this study. The study was approved by the Ethics and Radiation Safety Committee of the National Institute of Radiologic Sciences, Chiba, Japan.

\section{PET Procedure}

$(\mathrm{S}, \mathrm{S})-{ }^{18} \mathrm{~F}-\mathrm{FMeNER}-\mathrm{D}_{2}$ was synthesized by fluoromethylation of nor-ethyl-reboxetine with ${ }^{18} \mathrm{~F}$-bromofluoromethane- $\mathrm{d}_{2}$ as previously described (8). A PET scanner system (ECAT EXACT HR+; CTI-Siemens) was used for all subjects, with a head holder used to minimize head movement. A transmission scan for attenuation correction was performed using a ${ }^{68} \mathrm{Ge}-{ }^{68} \mathrm{Ga}$ source. Dynamic PET scans were performed after a 1-min intravenous slow bolus injection of 353.4-382.7 MBq (mean $\pm \mathrm{SD}, 368.1 \pm 9.1 \mathrm{MBq})$ of $(\mathrm{S}, \mathrm{S}){ }^{18}{ }^{18} \mathrm{~F}-$ FMeNER-D ${ }_{2}$. The specific radioactivity of $(\mathrm{S}, \mathrm{S})-{ }^{18} \mathrm{~F}-\mathrm{FMeNER}-\mathrm{D}_{2}$ was $144.8-390.2 \mathrm{GBq} / \mu \mathrm{mol}(312.8 \pm 76.2 \mathrm{GBq} / \mu \mathrm{mol})$. Brain radioactivities were measured from 0 to $90 \mathrm{~min}(1 \mathrm{~min} \times 10,2 \mathrm{~min} \times$ 15 , and $5 \mathrm{~min} \times 10$ ), from 120 to $180 \mathrm{~min}(10 \mathrm{~min} \times 6)$, and from 210 to $240 \mathrm{~min}(10 \mathrm{~min} \times 3)$. MR images of the brain were acquired with a 1.5-T MRI scanner (Gyroscan NT; Philips). T1-weighted images were obtained at $1-\mathrm{mm}$ slices.

\section{Arterial Blood Sampling and Metabolite Analysis}

To obtain the arterial input function, arterial blood samples were taken manually 42 times during the PET scan. Each blood sample was centrifuged to obtain plasma and blood cell fractions, and the concentrations of radioactivity in whole blood and in plasma were measured.

The percentage of unchanged $(\mathrm{S}, \mathrm{S})-{ }^{18} \mathrm{~F}-\mathrm{FMeNER}-\mathrm{D}_{2}$ in plasma was determined by high-performance liquid chromatography in 22 of the blood samples. Acetonitrile was added to each plasma sample, and samples were centrifuged. The supernatant was subjected to high-performance liquid chromatography radiodetection analysis (column: XBridge Prep C18, mobile phase, 90\% acetonitrile $/ 50 \mathrm{mM}$ ammonium acetate $=48 / 52$; Waters). Plasma input function was defined as radioactivity of plasma multiplied by the percentage of unchanged radioligand.

\section{Regions of Interest}

All MR images were coregistered to the PET images using a statistical parametric mapping system (SPM2; The Wellcome Trust
Centre for Neuroimaging, University College London). Regions of interest were drawn manually on summed PET images, with reference to coregistered MR images, and were defined for the thalamus, locus coeruleus, hippocampus, anterior cingulate gyrus, and caudate head. Regional radioactivity was calculated for each frame, corrected for decay, and plotted versus time.

\section{Kinetic Model of ${ }^{18} \mathrm{~F}-\mathrm{FMeNER}-\mathrm{D}_{2}$}

To describe the kinetics of $(\mathrm{S}, \mathrm{S})-{ }^{18} \mathrm{~F}-\mathrm{FMeNER}-\mathrm{D}_{2}$ in the brain, the 3-compartment model with 4 first-order rate constants was used. The 3 compartments were defined as follows: $C_{P}$ was the radioactivity concentration of unchanged radioligand in plasma (arterial input function), $\mathrm{C}_{\mathrm{ND}}$ was the radioactivity concentration of nondisplaceable radioligand in the brain, including nonspecifically bound and free radioligand, and $\mathrm{C}_{\mathrm{S}}$ was the radioactivity concentration of radioligand specifically bound to transporters. The rate constants $\mathrm{K}_{1}$ and $\mathrm{k}_{2}$ represent the influx and efflux rates, respectively, for radioligand diffusion through the blood-brain barrier, and the rate constants $\mathrm{k}_{3}$ and $\mathrm{k}_{4}$ are the radioligand transfers between the compartments for nondisplaceable and specifically bound radioligand, respectively. This model can be described by the following equations:

$$
\begin{gathered}
\frac{\mathrm{dC}_{\mathrm{ND}}(\mathrm{t})}{\mathrm{dt}}=\mathrm{K}_{1} \mathrm{C}_{\mathrm{P}}(\mathrm{t})-\left(\mathrm{k}_{2}+\mathrm{k}_{3}\right) \mathrm{C}_{\mathrm{ND}}(\mathrm{t})+\mathrm{k}_{4} \mathrm{C}_{\mathrm{S}}(\mathrm{t}), \\
\frac{\mathrm{dC}_{\mathrm{S}}(\mathrm{t})}{\mathrm{dt}}=\mathrm{k}_{3} \mathrm{C}_{\mathrm{ND}}(\mathrm{t})-\mathrm{k}_{4} \mathrm{C}_{\mathrm{S}}(\mathrm{t}) \text {, and } \\
\mathrm{C}_{\mathrm{T}}(\mathrm{t})=\mathrm{C}_{\mathrm{ND}}(\mathrm{t})+\mathrm{C}_{\mathrm{S}}(\mathrm{t}) .
\end{gathered}
$$

$\mathrm{C}_{\mathrm{T}}(\mathrm{t})$ is the total radioactivity concentration in any brain region measured by PET.

\section{Calculation of $(S, S)-{ }^{18} F-F M e N E R-D_{2}$ Binding Potential}

$(\mathrm{S}, \mathrm{S})-{ }^{18} \mathrm{~F}-\mathrm{FMeNER}-\mathrm{D}_{2}$ binding was quantified by the indirect kinetic, simplified reference-tissue model (SRTM), multilinear reference-tissue model (MRTM), and ratio methods. In these methods, $(\mathrm{S}, \mathrm{S})-{ }^{18} \mathrm{~F}-\mathrm{FMeNER}-\mathrm{D}_{2}$ bindings were expressed as binding potentials relative to nondisplaceable binding $\left(\mathrm{BP}_{\mathrm{ND}}\right)(13)$. We used the caudate as the reference brain region because of its

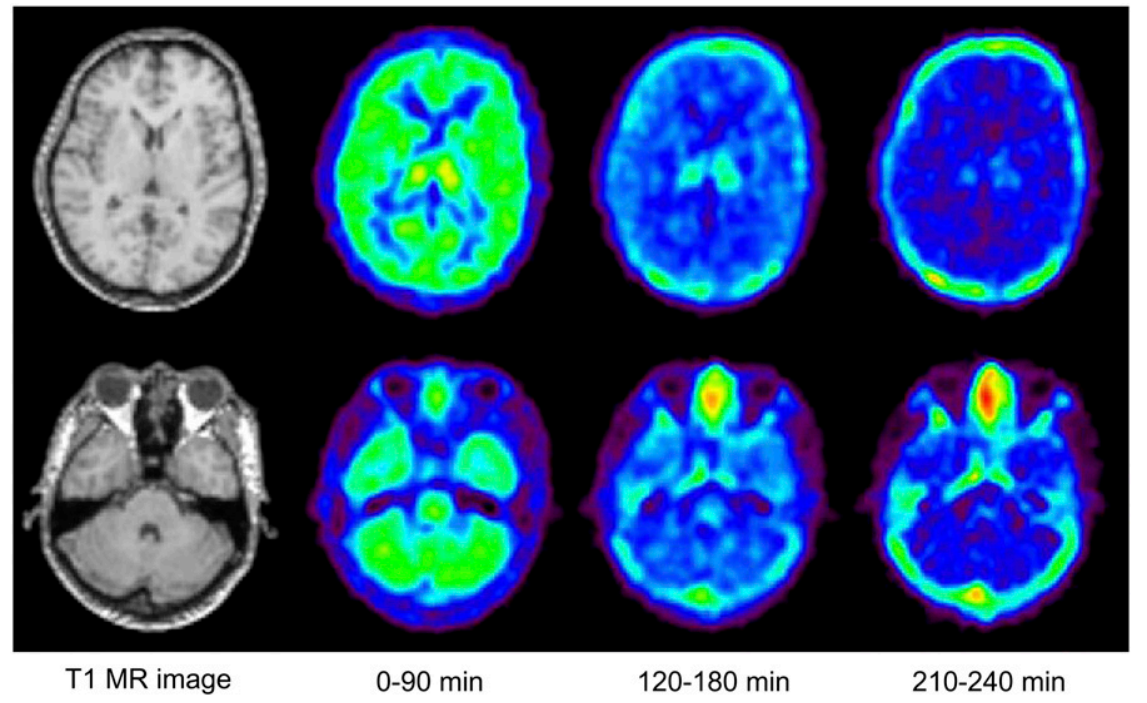

FIGURE 1. Typical summed PET images of $(\mathrm{S}, \mathrm{S}){ }^{-18} \mathrm{~F}-\mathrm{FMeNER}-\mathrm{D}_{2}$ and $\mathrm{T} 1$ weighted MR images. Upper panel shows slice of caudate and thalamus, and lower panel shows slice of locus coeruleus. 
negligible norepinephrine transporter density (14-16). Software (PMOD; PMOD Technologies) was used for these analyses.

\section{Indirect Kinetic Method}

With the caudate as reference region, $\mathrm{BP}_{\mathrm{ND}}$ can be expressed as:

$$
\mathrm{BP}_{\mathrm{ND}}=\frac{\mathrm{V}_{\mathrm{T}(\text { regions })}}{\mathrm{V}_{\mathrm{T} \text { (caudate })}}-1,
$$

where $\mathrm{V}_{\mathrm{T} \text { (regions) }}$ is the total distribution volume $\left(=\left[\mathrm{K}_{1} / \mathrm{k}_{2}\right]\left[\mathrm{k}_{3} / \mathrm{k}_{4}+\right.\right.$ 1]) of target regions and $\mathrm{V}_{\mathrm{T} \text { (caudate) }}$ is the total distribution volume of the caudate. The $\mathrm{K}_{1}, \mathrm{k}_{2}, \mathrm{k}_{3}$, and $\mathrm{k}_{4}$ values were determined by nonlinear least-squares curve fitting to the regional time-activity curves. In this analysis, blood volume $\left(\mathrm{V}_{\mathrm{b}}\right)$, which depends on the first-pass extraction fraction of the tracer, was also estimated using the radioactivity of whole blood to diminish the influence of the tracer remaining in the blood. In this study, the indirect kinetic method was used as the standard method (17).

\section{SRTM Method}

Assuming that both target and reference regions have the same level of nondisplaceable binding, the SRTM method can be used to describe time-activity data in the target region as follows (18):

$\mathrm{C}_{\mathrm{T}}(\mathrm{t})=\mathrm{R}_{1} \mathrm{C}_{\mathrm{R}}(\mathrm{t})+\left(\mathrm{k}_{2}-\mathrm{R}_{1} \frac{\mathrm{k}_{2}}{1+\mathrm{BP}_{\mathrm{ND}}}\right) \mathrm{C}_{\mathrm{R}}(\mathrm{t}) \otimes \exp \left(\frac{-\mathrm{k}_{2}}{1+\mathrm{BP}_{\mathrm{ND}}} \mathrm{t}\right)$,

where $R_{1}$ is the ratio of $K_{1} / K_{1}{ }^{\prime}\left(K_{1}\right.$, influx rate constant for the brain region; $\mathrm{K}_{1}{ }^{\prime}$, influx rate constant for the reference region), $\mathrm{C}_{\mathrm{R}}(\mathrm{t})$ is the radioactivity concentration in the reference region (caudate), and $\otimes$ denotes the convolution integral. Using this model, 3 parameters $\left(\mathrm{R}_{1}, \mathrm{k}_{2}\right.$, and $\left.\mathrm{BP}_{\mathrm{ND}}\right)$ were estimated by a nonlinear curve-fitting procedure. Scan data up to 180 or $240 \mathrm{~min}$ were used.

\section{MRTM Method}

The MRTM method is one of the variations of the graphical approaches (19). After a certain equilibrium time ( $\left.\mathrm{t}^{*}\right)$, the following multilinear regression is obtained:

$$
\begin{aligned}
\mathrm{C}_{\mathrm{T}}(\mathrm{T})= & -\frac{\mathrm{V}_{\mathrm{T}(\text { regions })}}{\mathrm{V}_{\mathrm{T}(\text { caudate })}} \int_{0}^{\mathrm{T}} \mathrm{C}_{\mathrm{R}}(\mathrm{t}) \mathrm{dt}+\frac{1}{\mathrm{~b}} \int_{0}^{\mathrm{T}} \mathrm{C}_{\mathrm{T}}(\mathrm{t}) \mathrm{dt} \\
& -\frac{\mathrm{V}_{\mathrm{T} \text { (regions) }}}{\mathrm{V}_{\mathrm{T} \text { (caudate })} \mathrm{k}_{2}{ }^{\prime} \mathrm{b}} \mathrm{C}_{\mathrm{R}}(\mathrm{T}),
\end{aligned}
$$

where $\mathrm{k}_{2}{ }^{\prime}$ is the efflux rate constant for the reference region. In this analysis, $t^{*}$ was determined so that the maximum error from the regression within the linear segment would be $10 \%$ for each time-activity curve. $\mathrm{BP}_{\mathrm{ND}}$ for the MRTM method was calculated using the same equation as described previously for the indirect kinetic method $\left(=\mathrm{V}_{\mathrm{T} \text { (regions) }} / \mathrm{V}_{\mathrm{T} \text { (caudate })}-1\right)$. Scan data up to 240 min were used.

\section{Ratio Method}

In the ratio method, $\mathrm{BP}_{\mathrm{ND}}$ can be expressed as:

$$
\mathrm{BP}_{\mathrm{ND}}=\frac{\mathrm{AUC}_{(\text {regions })}}{\mathrm{AUC}_{(\text {caudate })}}-1 \text {, }
$$

where $\mathrm{AUC}_{(\text {regions) }}$ is the area under the time-activity curve of the target regions and $\mathrm{AUC}_{\text {(caudate) }}$ is the area under the time-activity

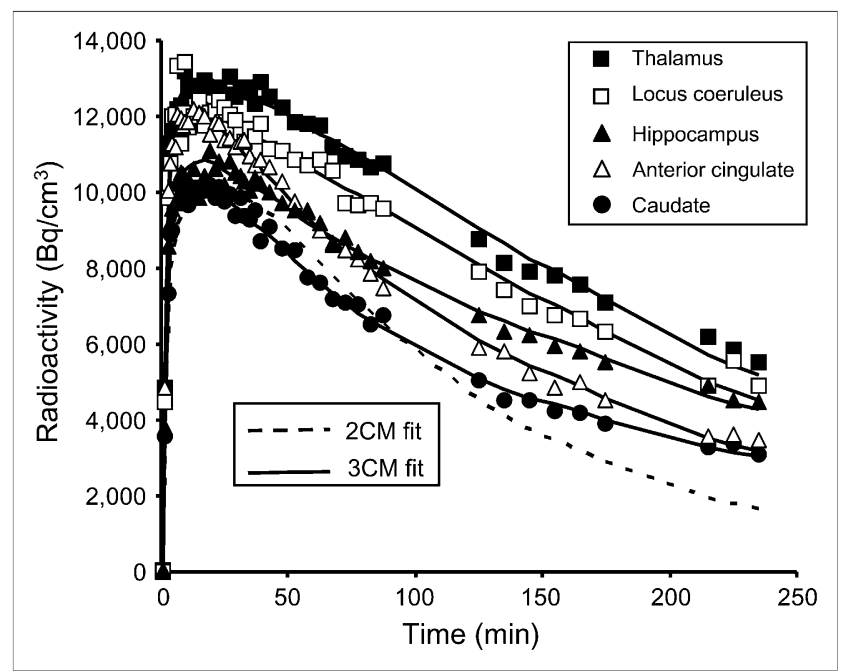

FIGURE 2. Typical time-activity curves of (S,S)-18F-FMeNER$\mathrm{D}_{2}$ in brain. Time-activity curves of all regions could be described by 3-compartment model (3CM). Time-activity curve of caudate could also be described by 2 -compartment model (2CM).

curve of the caudate. The integration interval of 120-180 min was used in this method.

\section{Simulation Study}

A simulation study was performed to estimate errors in $\mathrm{BP}_{\mathrm{ND}}$ calculated by the SRTM and ratio methods. Tissue time-activity curves for the thalamus were generated using the 3-compartment model. The rate constant values $\mathrm{K}_{1}, \mathrm{k}_{2}$, and $\mathrm{k}_{4}$ of the thalamus were assumed to be $0.157,0.037$, and 0.016 , respectively. The value of $\mathrm{k}_{3}$ ranged from 0.019 to 0.039 in 6 steps. Tissue timeactivity curves for the caudate were also generated using the 3-compartment model, assuming that the rate constant values $\mathrm{K}_{1}$, $\mathrm{k}_{2}, \mathrm{k}_{3}$, and $\mathrm{k}_{4}$ were $0.124,0.032,0.010$, and 0.010 , respectively. These assumed values were taken from the results obtained by the kinetic approach. The average of arterial input function for all

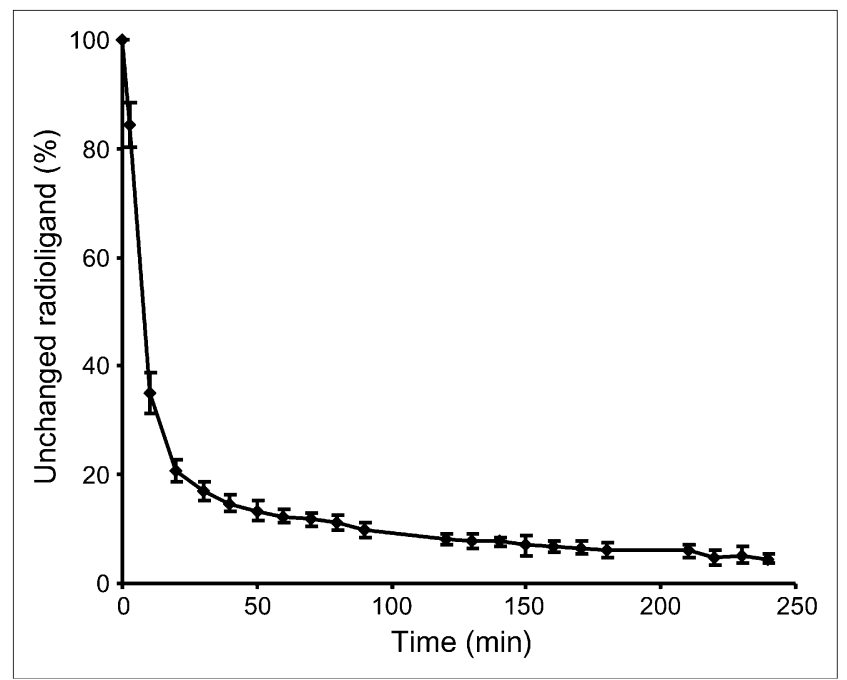

FIGURE 3. Average percentage of unchanged $(\mathrm{S}, \mathrm{S})-{ }^{18} \mathrm{~F}-$ FMeNER- $D_{2}$ in plasma. Bars indicate $1 \mathrm{SD}$. 
TABLE 1

Data for Each Brain Region Determined by Kinetic Approach Using 3-Compartment Model with Arterial Input Function

\begin{tabular}{|c|c|c|c|c|c|c|c|}
\hline \multirow[b]{2}{*}{ Region } & \multirow[b]{2}{*}{$V_{b}$} & \multicolumn{4}{|c|}{ Rate constant } & \multirow[b]{2}{*}{$\mathrm{V}_{\mathrm{ND}}$} & \multirow[b]{2}{*}{$\mathrm{V}_{\mathrm{T}}$} \\
\hline & & $\overline{\mathrm{K}_{1}(\mathrm{~mL} / \mathrm{mL} / \mathrm{min})}$ & $\mathrm{k}_{2}\left(\min ^{-1}\right)$ & $\mathrm{k}_{3}\left(\min ^{-1}\right)$ & $\mathrm{k}_{4}\left(\min ^{-1}\right)$ & & \\
\hline Thalamus & $0.045 \pm 0.016$ & $0.157 \pm 0.025$ & $0.037 \pm 0.005$ & $0.027 \pm 0.007$ & $0.016 \pm 0.002$ & $4.36 \pm 0.90$ & $11.45 \pm 2.29$ \\
\hline Locus coeruleus & $0.032 \pm 0.008$ & $0.154 \pm 0.026$ & $0.040 \pm 0.009$ & $0.020 \pm 0.008$ & $0.013 \pm 0.004$ & $4.06 \pm 1.01$ & $9.89 \pm 1.78$ \\
\hline Hippocampus & $0.038 \pm 0.010$ & $0.119 \pm 0.013$ & $0.035 \pm 0.011$ & $0.022 \pm 0.016$ & $0.015 \pm 0.005$ & $3.73 \pm 0.83$ & $8.48 \pm 1.14$ \\
\hline Anterior cingulate & $0.053 \pm 0.011$ & $0.144 \pm 0.019$ & $0.032 \pm 0.005$ & $0.010 \pm 0.005$ & $0.012 \pm 0.004$ & $4.61 \pm 1.04$ & $8.33 \pm 1.70$ \\
\hline $\begin{array}{l}\text { Caudate } \\
\text { (3-compartment } \\
\text { model) }\end{array}$ & $0.031 \pm 0.008$ & $0.124 \pm 0.018$ & $0.032 \pm 0.005$ & $0.010 \pm 0.005$ & $0.010 \pm 0.004$ & $3.92 \pm 0.80$ & $7.51 \pm 1.51$ \\
\hline $\begin{array}{l}\text { Caudate } \\
\text { (2-compartment } \\
\text { model) }\end{array}$ & $0.045 \pm 0.010$ & $0.109 \pm 0.017$ & $0.019 \pm 0.001$ & & & $5.77 \pm 0.98$ & \\
\hline
\end{tabular}

Values are mean $\pm S D . V_{N D}$ is defined as $K_{1} / k_{2}$ and $V_{T}$ as $\left(K_{1} / k_{2}\right)\left(k_{3} / k_{4}+1\right)$

subjects was used to generate the time-activity curves. With these generated time-activity curves, $\mathrm{BP}_{\mathrm{ND}}$ values were calculated by the SRTM (scan time of $240 \mathrm{~min}$ ), MRTM, and ratio methods. The calculated $\mathrm{BP}_{\mathrm{ND}}$ values for the simulation study were compared with those calculated by the indirect kinetic method.

\section{RESULTS}

Typical summed PET images of 3 time periods and T1-weighted MR images are shown in Figure 1. Typical time-activity curves in the brain showed that regional radioactivity was highest in the thalamus and lowest in the caudate (Fig. 2). Time-activity curves for all regions could be described by the 3-compartment model. The timeactivity curve for the caudate could also be described by the 2-compartment model. The average percentage of unchanged (S,S)- ${ }^{18} \mathrm{~F}-\mathrm{FMeNER}-\mathrm{D}_{2}$ in plasma was $84.4 \% \pm$ $3.9 \%$ at $3 \mathrm{~min}, 35.1 \% \pm 3.7 \%$ at $10 \mathrm{~min}, 10.0 \% \pm 1.4 \%$ at $90 \mathrm{~min}, 6.1 \% \pm 1.3 \%$ at $180 \mathrm{~min}$, and $4.5 \% \pm 0.9 \%$ at 240 min (Fig. 3).

The blood volume, rate constants, nondisplaceable distribution volume $\left(\mathrm{V}_{\mathrm{ND}}\right)$, and total distribution volume $\left(\mathrm{V}_{\mathrm{T}}\right)$ for each brain region determined by the kinetic approach using the 3-compartment model with arterial input function are shown in Table 1. For the caudate, the 2-compartment model without a specific binding compartment was also applied. Akaike information criteria of the 3-compartment model were lower than those of the 2-compartment model (143 \pm 16 vs. $227 \pm 6, P<0.0001$; paired $t$ statistics).

The $\mathrm{BP}_{\mathrm{ND}}$ values of the thalamus calculated by all methods are shown in Table 2. $\mathrm{BP}_{\mathrm{ND}}$ values in the thalamus by the MRTM method showed the best correlation with those by the indirect kinetic method $(r=0.92)$ (Fig. 4C). The SRTM method with scan times of 180 and 240 min and the ratio method also agreed with the $\mathrm{BP}_{\mathrm{ND}}$ values by the indirect kinetic method ( $r=0.81-0.91)$ (Figs. 4A, 4B, and $4 \mathrm{D})$. However, $\mathrm{BP}_{\mathrm{ND}}$ values in brain regions other than the thalamus could not be estimated by the SRTM and MRTM methods because of failed curve fitting, showing no con- vergence. The $\mathrm{BP}_{\mathrm{ND}}$ values of each brain region by the indirect kinetic and ratio methods are shown in Table 3. The correlation of $\mathrm{BP}_{\mathrm{ND}}$ values in all target regions between the indirect kinetic and the ratio methods is shown in Figure 5A. The Bland-Altman plot of $\mathrm{BP}_{\mathrm{ND}}$ values by these 2 methods is shown in Figure 5B.

In the simulation study, estimated $\mathrm{BP}_{\mathrm{ND}}$ values, compared with assumed $\mathrm{BP}_{\mathrm{ND}}$ values, by the SRTM (scan time of $240 \mathrm{~min}$ ), MRTM, and ratio methods were slightly overestimated (Fig. 6).

\section{DISCUSSION}

After intravenous injection of $(\mathrm{S}, \mathrm{S}){ }^{18}{ }^{18} \mathrm{~F}-\mathrm{FMeNER}-\mathrm{D}_{2}$, radioactivity was highest in the thalamus and lowest in the caudate. $\mathrm{BP}_{\mathrm{ND}}$ in the thalamus using the ratio method was $0.67 \pm 0.15$, almost the same value as found in a previous human PET study (10). The locus coeruleus showed relatively high uptake, and the hippocampus and anterior cingulate cortex showed relatively low uptake. This result was in agreement with previous reports that the thalamus and locus coeruleus showed high densities of norepinephrine transporters $(14-16,20)$. Previous autoradiographic studies with human postmortem brains reported that norepinephrine transporter density in the locus coeruleus was higher by about 10 times than that in the thalamus $(14,15)$. However,

TABLE 2

$\mathrm{BP}_{\mathrm{ND}}$ Values in Thalamus by All Methods

\begin{tabular}{lc}
\hline \multicolumn{1}{c}{ Method } & $\mathrm{BP}_{\mathrm{ND}}$ \\
\hline Indirect kinetic & $0.54 \pm 0.19$ \\
SRTM (240 min) & $0.61 \pm 0.14$ \\
SRTM (180 min) & $0.64 \pm 0.14$ \\
MRTM & $0.61 \pm 0.14$ \\
Ratio & $0.67 \pm 0.15$
\end{tabular}

Values are mean \pm SD. 
FIGURE 4. Correlation between $B P_{N D}$ values in thalamus estimated by indirect kinetic method and SRTM method with scan time of 240 min (A) or 180 min (B), MRTM method (C), or ratio method (D).
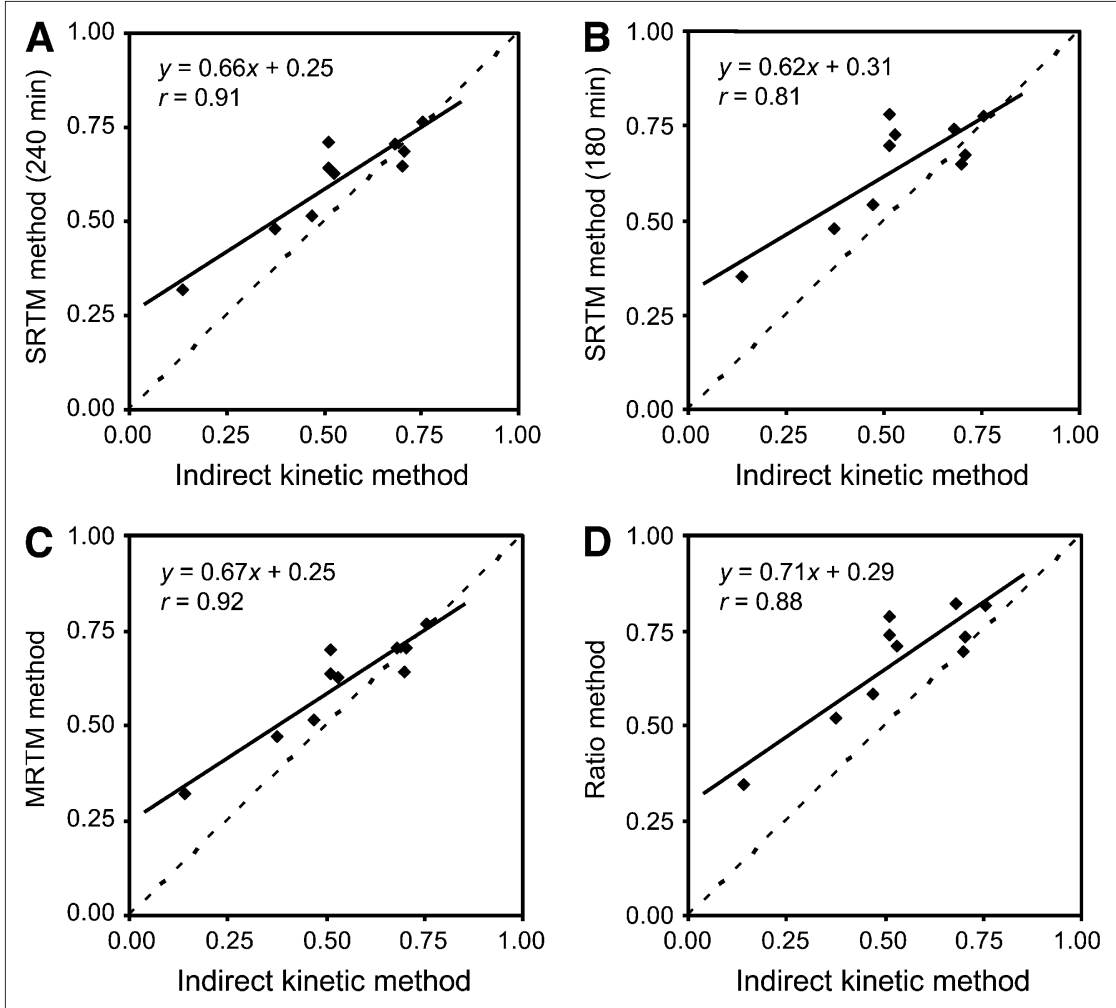

previous and present PET studies reported almost the same values between the locus coeruleus and thalamus $(10,16)$. One possible reason for the discrepancy was the partialvolume effect due to the limited spatial resolution of the PET scanner, the locus coeruleus being a very small structure.

In the current study, the indirect kinetic method with arterial blood sampling was used as the standard method (17). The $\mathrm{BP}_{\mathrm{ND}}$ values in the thalamus by the other 3 methods - the SRTM with scan times of 240 and $180 \mathrm{~min}$, MRTM, and ratio methods-were in agreement with those found by the indirect kinetic method. Although the indirect kinetic method was considered the standard method, it required a long PET time as well as arterial blood sampling, an invasive procedure particularly unsuitable for patients with psychiatric disorders. Because the ratio method does not require long PET and arterial blood sampling, this method would be preferable for clinical investigation. The SRTM and MRTM methods can estimate only the thalamus, as curve fitting failed in other brain regions. The MRTM2 method (19) may be able to estimate $\mathrm{BP}_{\mathrm{ND}}$ in regions other than thalamus; however, weighted $\mathrm{k}_{2}{ }^{\prime}$ value among brain regions could not be calculated in this tracer. The possible reasons of failed curve fitting might be the small differences of time-activity curves between target and reference regions and the noise in time-activity curves. The ratio method could reveal $\mathrm{BP}_{\mathrm{ND}}$ values in brain regions other than the thalamus. The $\mathrm{BP}_{\mathrm{ND}}$ values by the ratio method were in agreement with those by the indirect kinetic method for all brain regions (Fig. 5A). Although bias was observed by the ratio method, this bias did not change according to the $\mathrm{BP}_{\mathrm{ND}}$ values (Fig. 5B). The ratio method could estimate norepinephrine transporter binding in the thalamus and also other brain regions.

The time-activity curves in the caudate were better described by the 3-compartment model than the 2-compartment model. Similar results were reported for several PET radioligands; the kinetics in the reference region were also evaluated using the 3 -compartment model $(17,21,22)$. The results could be explained if the caudate contained specific binding for norepinephrine transporters. However, previous autoradiographic studies showed that the density of norepinephrine transporters in the caudate was very low (14-16). Another possible explanation is that the compartments of free and nonspecific binding could be separated by the kinetic analysis. Moreover, spillover from

TABLE 3

$\mathrm{BP}_{\mathrm{ND}}$ Values for Each Brain Region by Indirect Kinetic and Ratio Methods

\begin{tabular}{lcc}
\hline \multicolumn{1}{c}{ Region } & Indirect kinetic method & Ratio method \\
\hline Thalamus & $0.54 \pm 0.19$ & $0.67 \pm 0.15$ \\
Locus coeruleus & $0.35 \pm 0.25$ & $0.42 \pm 0.13$ \\
Hippocampus & $0.13 \pm 0.14$ & $0.23 \pm 0.09$ \\
\hline Anterior cingulate & $0.13 \pm 0.16$ & $0.15 \pm 0.09$
\end{tabular}

Values are mean \pm SD. 


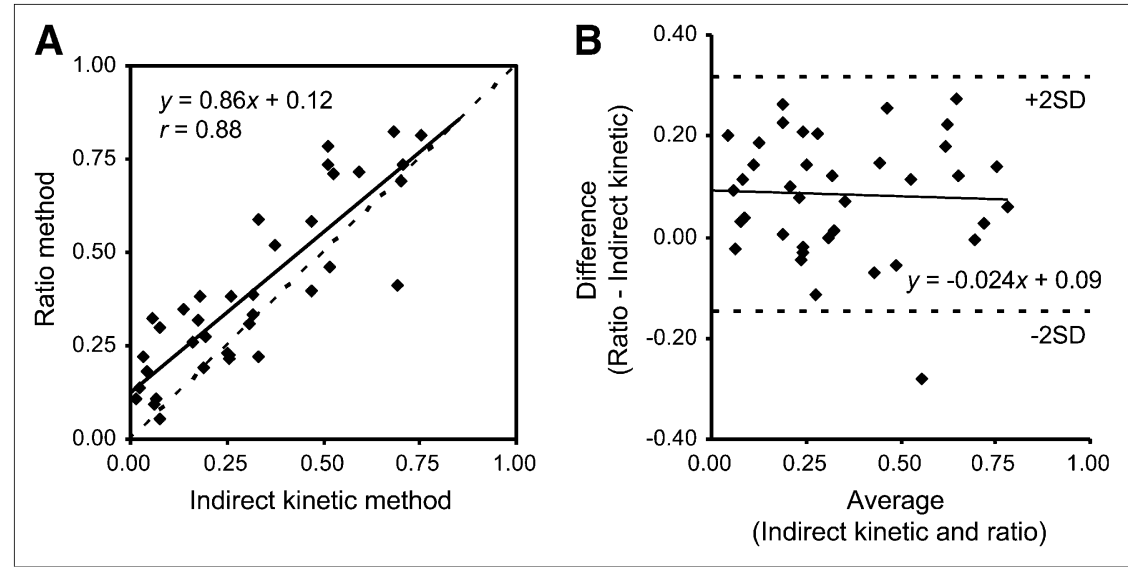

FIGURE 5. Correlation between $\mathrm{BP}_{\mathrm{ND}}$ values in all target regions estimated by indirect kinetic method and ratio method (A) and Bland-Altman plot (B). other brain regions to the caudate may affect the results because the caudate is a small structure and is surrounded by regions with specific binding.

In this study, we investigated norepinephrine transporter binding in only limited regions. Other brain regions such as the cerebral cortex and cerebellum are also considered to possess norepinephrine neurons and norepinephrine transporters (14-16). However, $(\mathrm{S}, \mathrm{S})-{ }^{18} \mathrm{~F}-\mathrm{FMeNER}-\mathrm{D}_{2}$ showed that defluorination and uptake of ${ }^{18} \mathrm{~F}$ in the skull influenced cerebral radioactivity $(8)$. Although $(\mathrm{S}, \mathrm{S})-{ }^{18} \mathrm{~F}-\mathrm{FMeNER}-\mathrm{D}_{2}$ had reduced defluorination by the dideuteration, compared with $(\mathrm{S}, \mathrm{S})-{ }^{18} \mathrm{~F}-\mathrm{FMeNER}$, estimation in the cerebral cortex or cerebellum adjacent to the skull was considered difficult.

In this study, occupancy of norepinephrine transporter by antidepressants was not evaluated. Previous animal studies showed dose-dependent norepinephrine transporter occupancy by atomoxetine (12). However, a human study using $\left[{ }^{11} \mathrm{C}\right](\mathrm{S}, \mathrm{S})-\mathrm{MRB}$ reported no differences in occupancy between different doses of atomoxetine (16). Further, occupancy studies in humans to estimate the clinical effects of antidepressants, similar to occupancy studies for dopamine $\mathrm{D}_{2}$ receptor and serotonin transporters $(23,24)$, will be needed.

In the simulation study, $\mathrm{BP}_{\mathrm{ND}}$ values by the $\mathrm{SRTM}$ with a scan time of $240 \mathrm{~min}$, MRTM, and the ratio methods were overestimated, compared with assumed $\mathrm{BP}_{\mathrm{ND}}$ (Fig. 6). Such overestimation was also observed in measured PET data, especially in regions with low specific binding (Figs. $4 \mathrm{~A}, 4 \mathrm{C}$, and 4D). The degree of overestimation of $\mathrm{BP}_{\mathrm{ND}}$ was larger in measured data than that in the simulation, especially in regions with low specific binding. Noise in measured data might cause such discrepancy, and therefore further studies using simulated data with added noise may be required. Although linear correlation was observed in $\mathrm{BP}_{\mathrm{ND}}$ values between the ratio and indirect kinetic methods, this overestimation may cause errors in the calculation of occupancy by antidepressants. When baseline $\mathrm{BP}_{\mathrm{ND}}$ is 0.6 , estimated occupancy by the ratio method is $22 \%, 43 \%$, and $65 \%$, corresponding to the assumed occupancy of $25 \%, 50 \%$, and $75 \%$, respectively (Fig. 6).
The SRTM and MRTM methods also showed the underestimation of occupancy, $21 \%, 43 \%$, and $64 \%$ by the former and $21 \%, 42 \%$, and $63 \%$ by the latter.

\section{CONCLUSION}

$(\mathrm{S}, \mathrm{S})-{ }^{18} \mathrm{~F}-\mathrm{FMeNER}-\mathrm{D}_{2}$ is a suitable radioligand for PET measurement of norepinephrine transporters in the human brain. The 3-compartment model could well describe the brain kinetics of $(\mathrm{S}, \mathrm{S})-{ }^{18} \mathrm{~F}-\mathrm{FMeNER}-\mathrm{D}_{2}$. Because the ratio method does not require long PET imaging times and arterial blood sampling, this method would be useful for clinical research of psychiatric disorders.

\section{ACKNOWLEDGMENTS}

We thank Dr. Fumitoshi Kodaka, Dr. Tatsui Otsuka, Katsuyuki Tanimoto, Takahiro Shiraishi, and Akira Ando

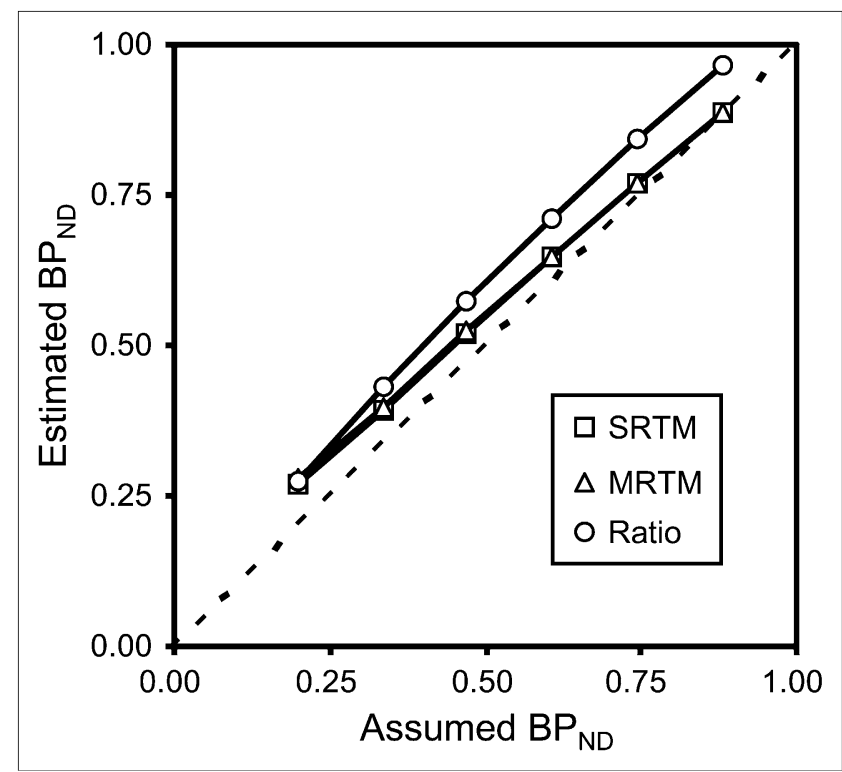

FIGURE 6. Correlations between assumed $\mathrm{BP}_{\mathrm{ND}}$ values by indirect kinetic method and those by SRTM with scan time of 240 min, MRTM method, or ratio method in simulation studies. 
for their assistance in performing the PET experiments at the National Institute of Radiological Sciences. We also thank Yoshiko Fukushima of the National Institute of Radiological Sciences for her help as clinical research coordinator. This study was supported by a consignment expense for the Molecular Imaging Program on Research Base for PET Diagnosis from the Ministry of Education, Culture, Sports, Science and Technology (MEXT), Japanese government, and by a Health and Labor Sciences Research Grant for Research on Psychiatric and Neurological Diseases and Mental Health from the Ministry of Health, Labor and Welfare, Japanese government.

\section{REFERENCES}

1. Harmer CJ, Shelley NC, Cowen PJ, Goodwin GM. Increased positive versus negative affective perception and memory in healthy volunteers following selective serotonin and norepinephrine reuptake inhibition. Am J Psychiatry. 2004;161:1256-1263.

2. Strange BA, Hurlemann R, Dolan RJ. An emotion-induced retrograde amnesia in humans is amygdala- and beta-adrenergic-dependent. Proc Natl Acad Sci USA. 2003;100:13626-13631.

3. Southwick SM, Davis M, Horner B, et al. Relationship of enhanced norepinephrine activity during memory consolidation to enhanced long-term memory in humans. Am J Psychiatry. 2002;159:1420-1422.

4. Nutt DJ. The role of dopamine and norepinephrine in depression and antidepressant treatment. J Clin Psychiatry. 2006;67(suppl 6):3-8.

5. Cheng JY, Chen RY, Ko JS, Ng EM. Efficacy and safety of atomoxetine for attention-deficit/hyperactivity disorder in children and adolescents: meta-analysis and meta-regression analysis. Psychopharmacology (Berl). 2007;194:197-209.

6. Chamberlain SR, Del Campo N, Dowson J, et al. Atomoxetine improved response inhibition in adults with attention deficit/hyperactivity disorder. Biol Psychiatry. 2007;62:977-984.

7. Shelton RC. The dual-action hypothesis: does pharmacology matter? J Clin Psychiatry. 2004;65(suppl 17):5-10.

8. Schou M, Halldin C, Sovago J, et al. PET evaluation of novel radiofluorinated reboxetine analogs as norepinephrine transporter probes in the monkey brain. Synapse. 2004;53:57-67.

9. Seneca N, Andree B, Sjoholm N, et al. Whole-body biodistribution, radiation dosimetry estimates for the PET norepinephrine transporter probe (S,S)$\left[{ }^{18}\right.$ F]FMeNER-D2 in non-human primates. Nucl Med Commun. 2005;26:695-700.
10. Takano A, Gulyas B, Varrone A, et al. Imaging the norepinephrine transporter with positron emission tomography: initial human studies with (S,S)$\left[{ }^{18}\right.$ F]FMeNER-D 2 . Eur J Nucl Med Mol Imaging. 2008;35:153-157.

11. Takano A, Halldin C, Varrone A, et al. Biodistribution and radiation dosimetry of the norepinephrine transporter radioligand $(\mathrm{S}, \mathrm{S})-\left[{ }^{18} \mathrm{~F}\right] \mathrm{FMeNER}-\mathrm{D}_{2}$ : a human whole-body PET study. Eur J Nucl Med Mol Imaging. 2008;35:630-636.

12. Seneca N, Gulyas B, Varrone A, et al. Atomoxetine occupies the norepinephrine transporter in a dose-dependent fashion: a PET study in nonhuman primate brain using (S,S)-[ ${ }^{18}$ F]FMeNER-D2. Psychopharmacology (Berl). 2006;188: 119-127.

13. Innis RB, Cunningham VJ, Delforge J, et al. Consensus nomenclature for in vivo imaging of reversibly binding radioligands. J Cereb Blood Flow Metab. 2007;27: 1533-1539.

14. Schou M, Halldin C, Pike VW, et al. Post-mortem human brain autoradiography of the norepinephrine transporter using (S,S)-[18F]FMeNER-D2. Eur Neuropsychopharmacol. 2005; 15:517-520.

15. Donnan GA, Kaczmarczyk SJ, Paxinos G, et al. Distribution of catecholamine uptake sites in human brain as determined by quantitative $\left[{ }^{3} \mathrm{H}\right]$ mazindol autoradiography. J Comp Neurol. 1991;304:419-434.

16. Logan J, Wang GJ, Telang F, et al. Imaging the norepinephrine transporter in humans with $(\mathrm{S}, \mathrm{S})-\left[{ }^{11} \mathrm{C}\right] \mathrm{O}$-methyl reboxetine and PET: problems and progress. Nucl Med Biol. 2007;34:667-679.

17. Ito H, Sudo Y, Suhara T, Okubo Y, Halldin C, Farde L. Error analysis for quantification of $\left[{ }^{11} \mathrm{C}\right] \mathrm{FLB} 457$ binding to extrastriatal $\mathrm{D}_{2}$ dopamine receptors in the human brain. Neuroimage. 2001;13:531-539.

18. Lammertsma AA, Hume SP. Simplified reference tissue model for PET receptor studies. Neuroimage. 1996;4:153-158.

19. Ichise M, Liow JS, Lu JQ, et al. Linearized reference tissue parametric imaging methods: application to $\left[{ }^{11} \mathrm{C}\right] \mathrm{DASB}$ positron emission tomography studies of the serotonin transporter in human brain. J Cereb Blood Flow Metab. 2003;23:10961112 .

20. Ordway GA, Stockmeier CA, Cason GW, Klimek V. Pharmacology and distribution of norepinephrine transporters in the human locus coeruleus and raphe nuclei. J Neurosci. 1997;17:1710-1719.

21. Lundberg J, Odano I, Olsson H, Halldin C, Farde L. Quantification of ${ }^{11} \mathrm{C}-$ MADAM binding to the serotonin transporter in the human brain. $J$ Nucl Med. 2005;46:1505-1515.

22. Farde L, Ito H, Swahn CG, Pike VW, Halldin C. Quantitative analyses of carbonyl-carbon-11-WAY-100635 binding to central 5-hydroxytryptamine-1A receptors in man. J Nucl Med. 1998;39:1965-1971.

23. Takano A, Suzuki K, Kosaka J, et al. A dose-finding study of duloxetine based on serotonin transporter occupancy. Psychopharmacology (Berl). 2006;185:395399.

24. Arakawa R, Ito H, Takano A, et al. Dose-finding study of paliperidone ER based on striatal and extrastriatal dopamine $\mathrm{D}_{2}$ receptor occupancy in patients with schizophrenia. Psychopharmacology (Berl). 2008;197:229-235. 